\title{
Endoscopic submucosal dissection of intramucosal adenocarcinoma on Barrett's esophagus
}

A 63-year-old man was investigated because of long-standing pathological gastroesophageal reflux. Diagnostic endoscopy showed long-segment Barrett's esophagus associated with a flat lesion compatible with a granular laterally spreading tumor (LST-G), and endoscopic submucosal dissection was decided upon [1].

A Fujinon EG-590-ZW diagnostic endoscope was used for the procedure. A Fujinon transparent conical cup and Fujifilm 1.5-mm FlushKnife BT were used as the dissecting instruments.

The endoscope was advanced to the distal esophagus, where long-segment Barrett's esophagus (6cm in length) was confirmed. In addition, a homogeneous flat lesion compatible with a LST-G of $4 \mathrm{~cm}$ maximum diameter was shown ( Fig. 1 ).

Flexible spectral imaging color enhancement (FICE) and magnification were used for exhaustive assessment of the surface and margins of the lesion, which presented a granular flat segment on its edges.

The edges of the lesion were marked with a safety margin of $5 \mathrm{~mm}$ ( $\mathbf{F i g . 2}$ ). The lesion was then raised by submucosal injection with a solution made up of $500 \mathrm{~mL}$ Voluven, $2.5 \mathrm{~mL}$ methylene blue, and $1 \mathrm{mg}$ epinephrine. A complete perimeter mucotomy, external to the marking, was performed (> Fig.3). Careful hemostasis was carried out, followed by endoscopic dissection of the submucosal layer adjacent to the muscularis propria ( $>$ Fig.4) [2]. The entire submucosal layer of the lesion in the dissected specimen was included. The surgical bed was undamaged, with no signs of perforation and correct hemostasis ( $\mathbf{F i g . 5}$; - Video 1 ).

At 6-month post-procedure follow-up the wound had healed. Re-epithelialization with squamous mucosa without evidence of esophageal stenosis was

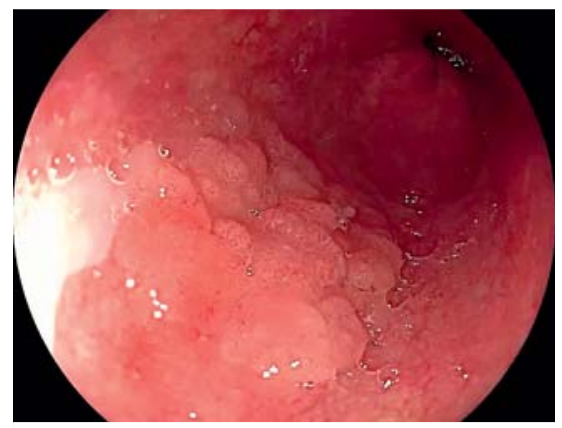

- Fig. 1 Granular laterally spreading tumor in the esophagus of a 63-year-old man.

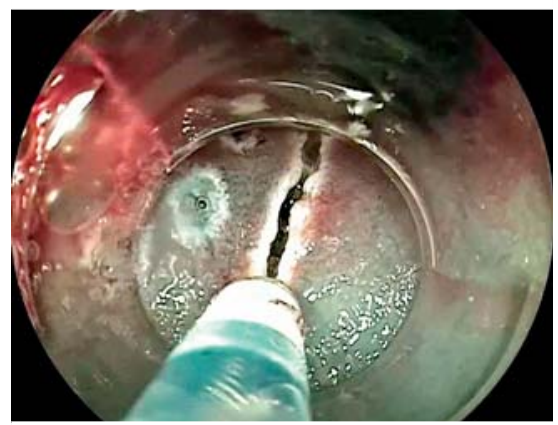

-Fig. 3 Perimeter mucotomy was performed external to the marking.

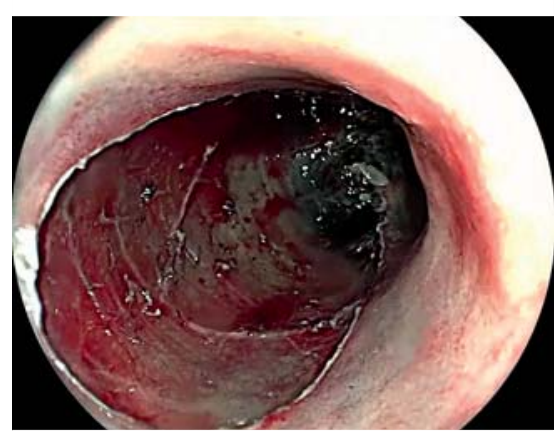

Fig. 5 The surgical bed was undamaged.

demonstrated. On this occasion, the remaining Barrett's esophagus was ablated using radiofrequency.

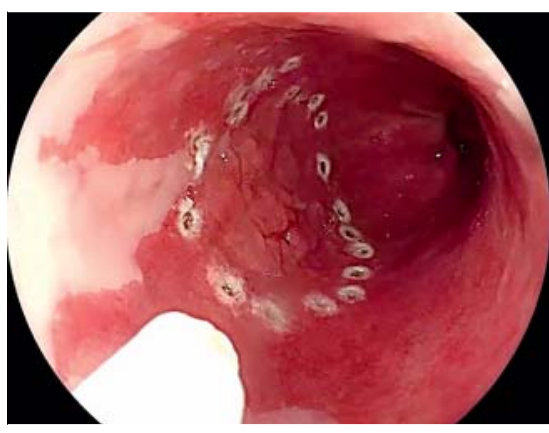

Fig. 2 The edges of the lesion were marked with a safety margin of $5 \mathrm{~mm}$

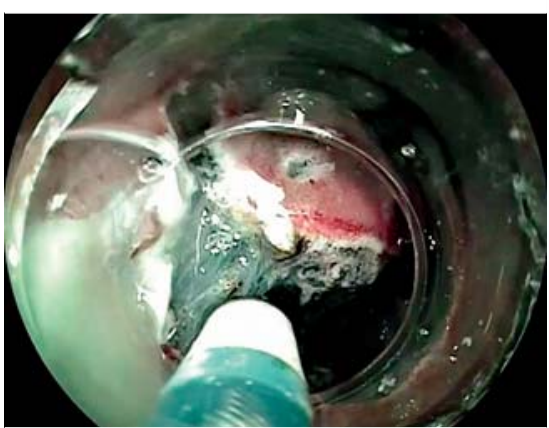

Fig. 4 The submucosal layer adjacent to the muscularis propria was dissected.

The pathological report was of well-differentiated, intramucosal adenocarcinoma without compromise of lateral or deep margins.

Carrying out ESD for incipient neoplastic lesions in Barrett's esophagus is feasible and safe [3] and achieves good oncological results. It should be followed by radiofrequency ablation of the remaining Barrett's esophagus [4,5].

Endoscopy_UCTN_Code_TTT_1AO_2AG

Competing interests

The authors declare that they have no conflict of interest. 


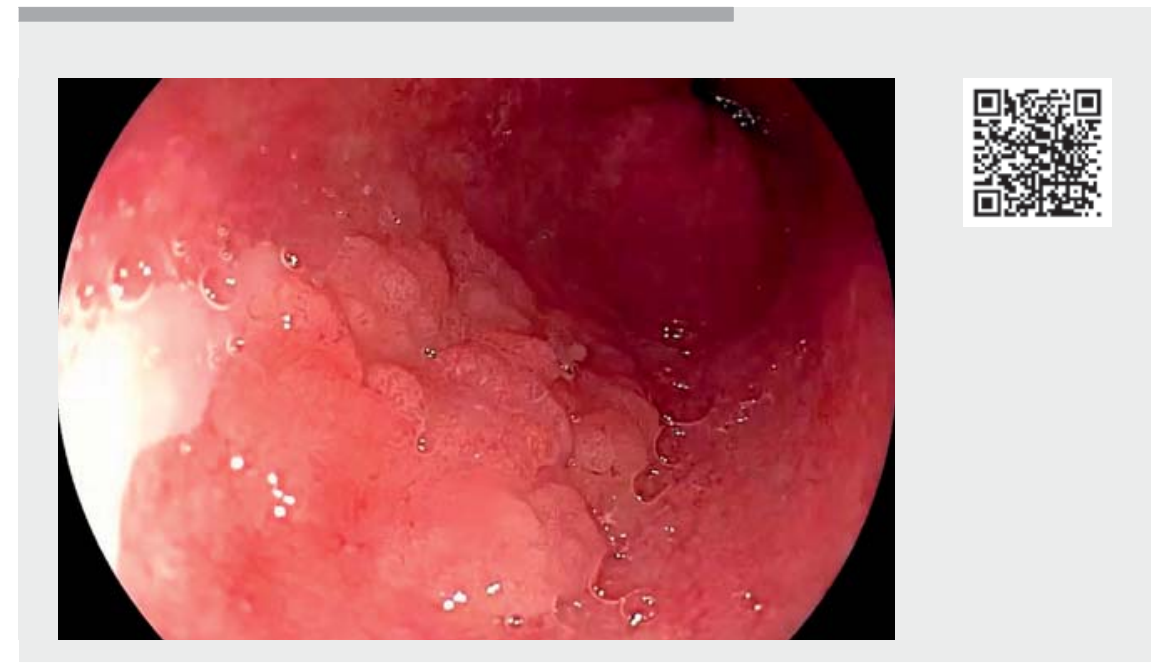

$\checkmark$ Video 1 Endoscopic submucosal dissection of the distal esophagus.

The authors

Sergio Rubel Cohen, Damián Orellano, Daniel Castellón García, César Acevedo Sylvester Therapeutic Diagnostic Endoscopic Center (CEDIT), Barros Luco Trudeau Hospital, Santiago, Chile

Corresponding author

\section{Sergio Rubel Cohen, MD}

Hospital Barros Luco Trudeau - CEDIT, Gran Avenida Jose Miguel Carrera 3204, Santiago, San Miguel, Región Metropolitana Santiago de Chile 8900085, Chile

sergiorubelcohen@gmail.com
[5] Frei N, Frei R, Semadeni GM et al. Endoscopic treatment of early Barrett's adenocarcinoma and dysplasia: focus on submucosal cancer. Digestion 2019; 99: 293-300

\section{Bibliography}

Endoscopy 2022; 54: E329-E330

DOI 10.1055/a-1508-5273

ISSN 0013-726X

published online 19.7.2021

(c) 2021. Thieme. All rights reserved.

Georg Thieme Verlag KG, Rüdigerstraße 14,

70469 Stuttgart, Germany

ENDOSCOPY E-VIDEOS

https://eref.thieme.de/e-videos

口回 Endoscopy E-Videos is an open access online section, 回释: reporting on interesting cases and new techniques in gastroenterological endoscopy. All papers include a high quality video and all contributions are freely accessible online. Processing charges apply (currently EUR 375), discounts and wavers acc. to HINARI are available.

This section has its own submission website at

https://mc.manuscriptcentral.com/e-videos 